\title{
Assessment of Potential Suitable Surface Irrigation Area in Borkena River Catchment, Awash Basin, Ethiopia
}

\author{
Kasye Shitu ${ }^{1}$, Shemelis Berhanu ${ }^{2}$ \\ ${ }^{1}$ Department of Soil and Water Resource Management, Assosa University, Assosa, Ethiopia \\ ${ }^{2}$ School of Water Resource and Environmental Engineering, Haramaya Institute of Technology, Haramaya University, Haramaya, Ethiopia
}

Email address:

kasye61921@gmai.com(K. Shitu),shemelisberhanu@yahoo.com (S.Berhanu)

To cite this article:

Kasye Shitu, Shemelis Berhanu. Assessment of Potential Suitable Surface Irrigation Area in Borkena River Catchment, Awash Basin, Ethiopia. Journal of Water Resources and Ocean Science. Vol. 9, No. 5, 2020, pp. 98-106. doi: 10.11648/j.wros.20200905.12

Received: March 18, 2020; Accepted: April 15, 2020; Published: September 24, 2020

\begin{abstract}
Although Ethiopia has abundant land for irrigation, only a fraction of its potential land is being utilized and the economy of the country subjected to a direct impact of climate change. So, assessment of land suitability for irrigation purpose is important to utilize the land resources efficiently and for the sustainable production of crops and food security of the ever increasing people in the country especially the study area. This study was initiated to assess the land resources which is potentially suitable for surface irrigation in Borkena watershed by using Geographic Information System (GIS). To identify the land which is suitable for irrigation purpose, the following factors such as soil type, slope, land use/cover and distance from water supply (sources) were taken into account and classified based on the FAO guideline for land evaluation in to S1, S2, S3 and N suitability classes independently. The final existing and potentially irrigable land was identified by weighting overlay these factors of suitability. The suitability analysis of the parameters indicates that $90.65 \%$ of slope, $72.03 \%$ of soil depth, $94.73 \%$ distance from a water source of the study area, $100 \%$ soil drainages and $100 \%$ of soil texture were identified in the range of highly suitable (S1) to marginal suitable (S3) for surface irrigation. But, when all the above physical suitable area determination factors were weighted together using weighted overlay in Arc GIS software by restricted other land use/cover for irrigation development without agricultural land indicates only $16.13 \%$ highly suitable (S1), 47.12\% moderately suitable (S2), 31.58 marginally suitable (S3) and 5.17\% non-suitable (N) area for surface irrigation development.
\end{abstract}

Keywords: GIS, Land Suitability, Irrigation, Borkena River Catchment

\section{Introduction}

Ethiopia is one of the African countries whose economy is largely dependent on agriculture [1]. However, this economy is subjected to a direct impact of climate change. Because, large portion of lands in Ethiopia are arid or semi-arid, inhabited by poor and vulnerable communities wholly dependent on rainfall. In addition, poor land management coupled with increasing climate extremes is affecting the livelihoods of these communities [2-4]. For these enhancing public and private investments in irrigation development has been identified as one of the core strategies which aimed to change economic performance from rainfall and enable sustainable growth and development in the country [1, 5-6]. In addition to this by considering the current population growth rate and food insecurity in the country [7-9] and [10] indicates that development of irrigation plays an important role in stimulating economic growth and rural development by increasing and stabilizing agricultural production and productivity of the country.

However, implementation of such strategies requires a thorough assessment of land suitability for irrigation purpose to utilize the land resources in efficiently way for the sustainable production of crops and food security of the ever increasing people in the country [11]. So, scientific evidence on surface irrigation suitability in the single River catchment also vital for policymakers, researcher, and planner along with the farmers to formulate the adaptation and mitigation options for developing supplementary irrigation. Because, evaluating and assessing of the potential and suitable land area will provide a comprehensive and integrated economic viability and sustainability for water and land resource development. Also, since, all kinds of rural land are 
involved by different land- use/ cover type, assessing available land resources for irrigation provides guidance in cases of conflict management between rural land use and urban or industrial expansion, by indicating which areas of land uses/cover are most suitable for irrigation [12]. So, the general, aim of this study was to assess the potentially suitable area for surface irrigation in Borkena River Catchment Awash Basin, Ethiopia.

\section{Method of Data Collection and Analysis}

\subsection{Location}

(5) The study was conducted in Borkena River catchment, Awash Basin, Ethiopia, which is located at $10^{\circ} 36^{\prime} 0^{\prime \prime}$ $11^{\circ} 24^{\prime} 0 " \mathrm{~N}$ latitude and $39^{\circ} 24^{\prime} 0^{\prime \prime}-40^{\circ} 12^{\prime} 0^{\prime \prime}$ E longitudes. The total area and the longest flow path towards the outlet of Borkena River catchment is $1,260 \mathrm{~km}^{2}$ and $85 \mathrm{~km}$ respectively which obtained from the DEM delineation of the River catchment. It is one of the main tributaries of the Awash River and originated from mountainous chains and escapements found in the Northern plateau at an elevation of 3,408 $\mathrm{m}$ a.s.1 and drains to adjacent of Afar, Rift Valley down to Southeastern direction at an elevation of $1,427 \mathrm{~m}$ a.s.l.

\subsection{Data Collection}

To achieve the objectives of the study different data inputs were collected from the study area and from different sources such as, soil data from GIS and Remote Sensing Department, Ministry of Water, Irrigation and Electricity of Ethiopia as a shape file of the Awash River Basin for the year 2017, in addition to this survey report of the River catchment soil, related to textural class, depth and drainages were collected from Amhara National Regional State well Enterprise Office Kombolcha Branch and the land use/land cover data was obtained from GIS and Remote Sensing Department, Ministry of Water, Irrigation and Electricity of Ethiopia as a shape file of the Awash River Basin in the year 2017and GPS reading Point data from the study area. Materials used to successfully perform the research were including Arc GIS10.7.

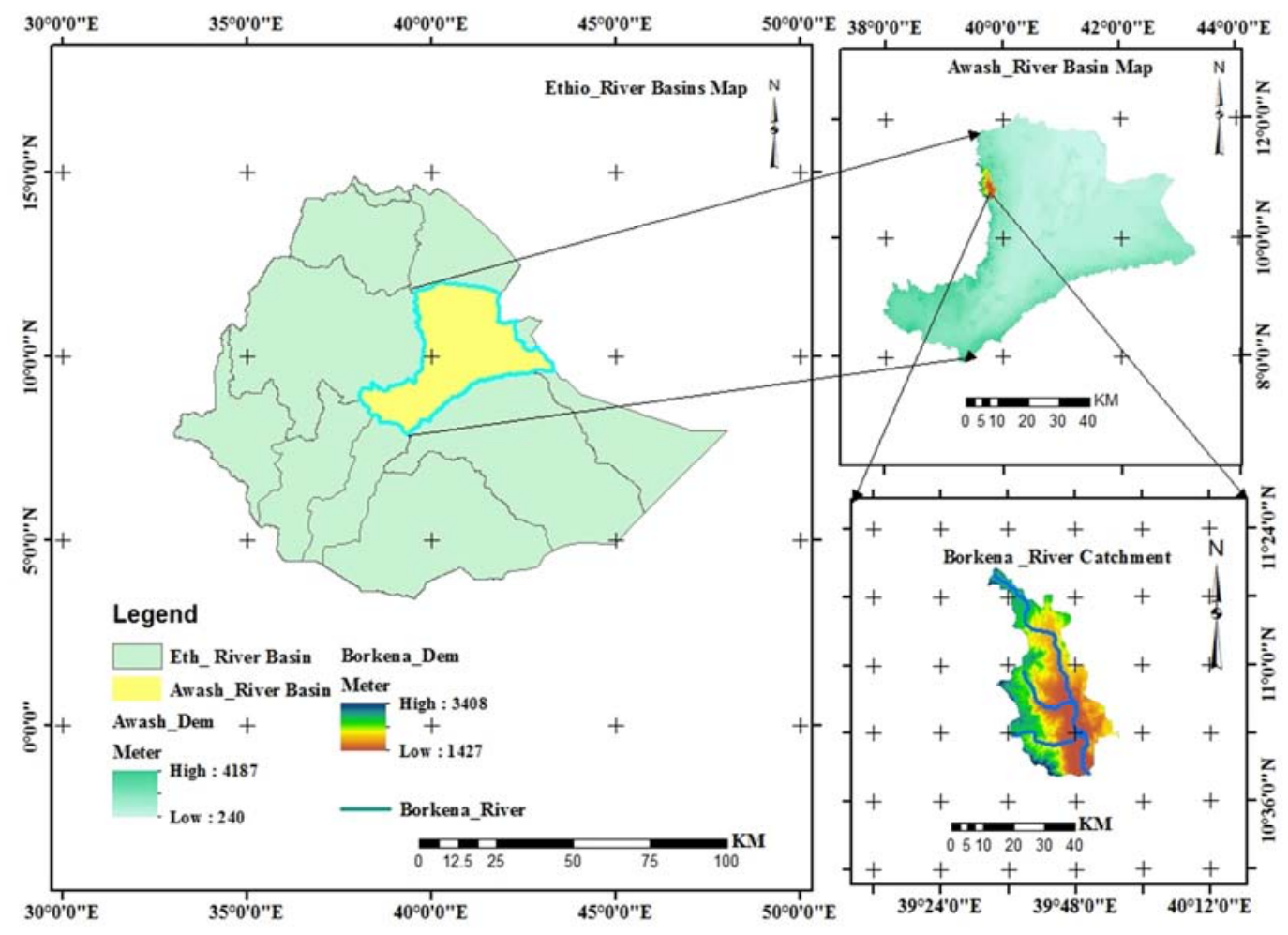

Figure 1. Location map of the study area.

\subsection{Methods}

Analyses of data were carried out for each physical land suitability factors to evaluate suitability nature the River catchment for surface irrigation. The main irrigation suitability factors undertaken during the study were slope, soil texture, soil drainage, soil depth, land use/cover and Euclidean distance from the water source.
The suitability of each factors were analyzed separately and finally they were weighted together to get existing and potential irrigable sites in the River catchment.

\subsubsection{Soil Suitability Analysis}

The analysis of soil suitability for this study was conducted in the following ways firstly each soil physical parameters (soil texture, soil drainage and soil depth) were 
prepared as feature layers in GIS software. Second the feature layers of the parameters were converted into a raster layer using the conversion tool to raster and finally soil suitability map of each soil physical parameter was classified with the factor rate of S1, S2, S3, and N through reclassified the raster layers based on the FAO [13-15] soil suitability classification for surface irrigation (Table 1).

Table 1. Soil and slope suitability factor rating for irrigation suitability analysis.

\begin{tabular}{lllll}
\hline \multirow{2}{*}{ Factors } & \multicolumn{2}{l}{ Factor rating } & \\
\cline { 2 - 5 } & S1 & S2 & S3 & N \\
\hline Drainage class & Well & Imperfect & Poor & Very poor \\
\hline Soil depth $(\mathrm{cm})$ & $>100$ & $80-100$ & $50-80$ & $<50$ \\
Soil texture & L, CL, C & SiL, SCL & S, SL & \\
Slope $(\%)$ & $<2$ & $2-5$ & $5-8$ & $>8$ \\
\hline
\end{tabular}

\subsubsection{Slope and Euclidean Distance Suitability Analysis}

Slope and Euclidean distance map of the study area was derived from DEM of $30 \mathrm{~m}$ by $30 \mathrm{~m}$ spatial resolution using the "Spatial Analysis Slope" tool in Arc GIS and classified based on the classification system of FAO [16] using the "Reclassification" tool in to suitability classes and Finally slope suitability map and Euclidean distance map were developed and data layers were prepared for further overlay analysis.

\subsubsection{Land Use/Land Cover}

In this study the land use /land cover classification was extracted by musk from the land use/cover data of the Awash River Basin, then the area coverage of each land use was determined by Arc GIS 10.7 and data layer was prepared for further overlay analysis with other factors.

\subsubsection{Weighing of Irrigation Suitability Factors}

Irrigation suitability of each parameter were assessed and their suitability map layer of each criterion were developed separately, after that an overlay analysis was done to generate one suitability map of the River catchment using "model builder" in Arc tools box and tools from spatial analysis tool sets.

\section{Results and Discussion}

\subsection{Soil Suitability Analysis}

The soil suitability analysis of the River catchment for surface irrigation based on FAO [13] suitability classification of soil physical parameters (drainage, texture and depth) were indicated in the following section.

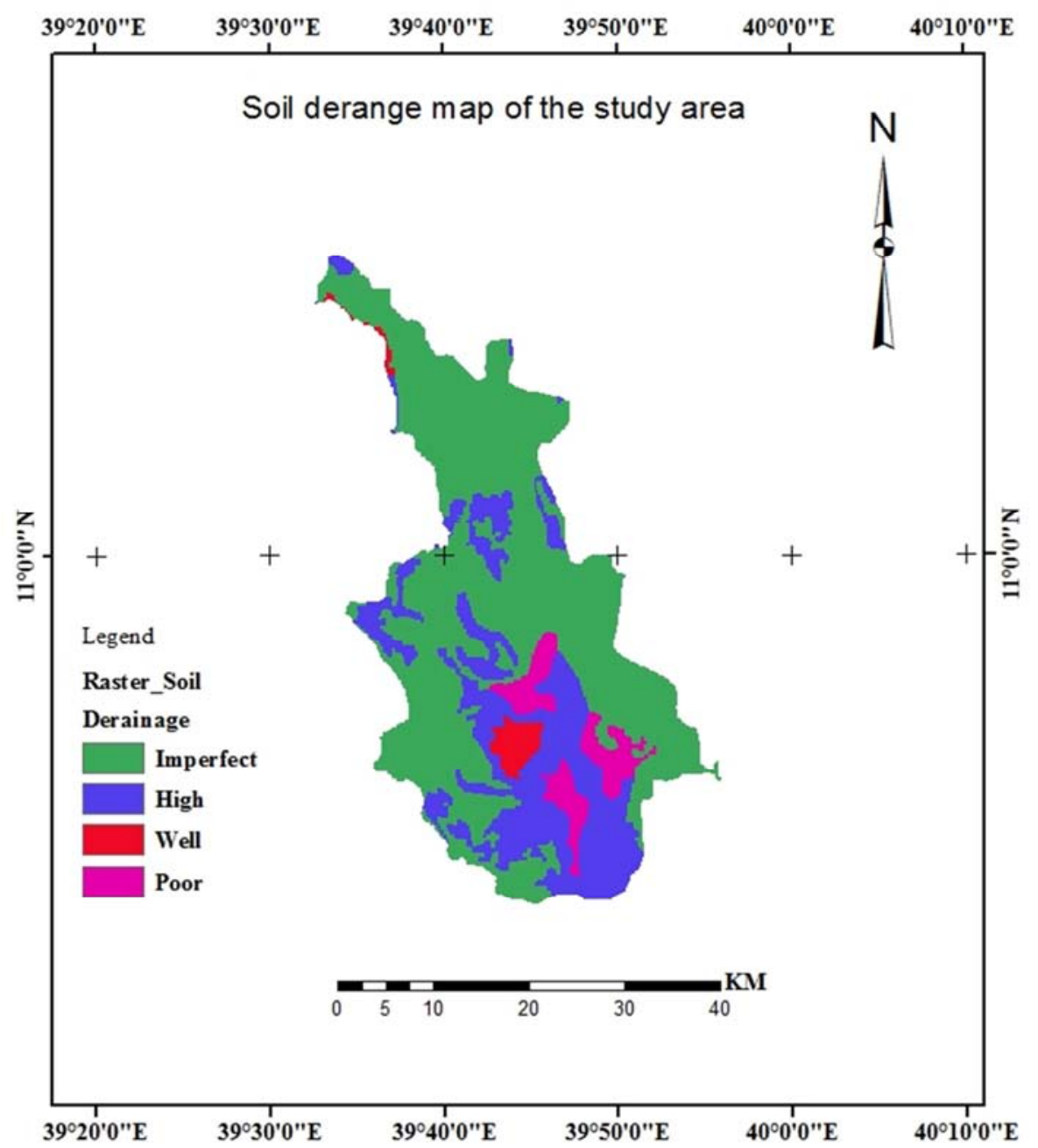

Figure 2. Soil derange map of Borkena River catchment. 
According to FAO [13] soil permeability evaluation techniques, the soil drainage of the River catchment was grouped as high (excessive drained), well, poorly and imperfect drained conditions (Figure 2) and (Table 2). Since most part of the study area were dominated by imperfect drained soil (Figure 2), the River catchment was characterized by moderately suitable (S2) area for surface irrigation with high percentage ratio (Table 2) and also around 8,276.00ha (6.57\%) and 33,083 (26.26\%) of the River catchment occurring under Poor and high soil drainage respectively, which is suitable for marginal (S3) surface irrigation development. Due to this nature of soil of the River catchment, only $2.55 \%$ of the River catchment was classified under well drainage soil class which is highly suitable (S1).

Based on FAO [13] soil textural suitability classification for surface irrigation as shown in Figure 3 and Table 3 the textural class of the River catchment soil ranges from highly suitable (S1) to marginally suitable (S3). Table 3 also indicates most areas of the River catchment $(65.29 \%)$ was covered with clay loam soil textural class, which is highly suitable (S1) for surface irrigation practice. A soil textural class clay, sandy clay loam, and sandy loam have area coverage of $7.73 \%, 2.53 \%$ and $16.43 \%$ and irrigation suitability class of highly suitable (S1), moderately suitable (S2) and marginally suitable (S3) for surface irrigation respectively. From soil textural suitability classification for surface irrigation, most areas of Borkena River catchment (73.02\%) were classified under highly suitable (S1) class, $24.45 \%$ of the area was classified under marginally suitable (S3) class and $2.53 \%$ of the area was classified under moderately suitable (S2) class.

Table 2. Areal distribution of drainage class of Borkena River catchment soil.

\begin{tabular}{llll}
\hline Drainage Conditions & Area (ha) & Area (\%) & Class \\
\hline High & 33,083 & 26.26 & $\mathrm{~S} 3$ \\
Well & 3,209 & 2.55 & $\mathrm{~S} 1$ \\
Poor & 8,276 & 6.57 & $\mathrm{~S} 3$ \\
Imperfect & 81,432 & 64.62 & $\mathrm{~S} 2$ \\
Total & 126,000 & 100.00 & \\
\hline
\end{tabular}

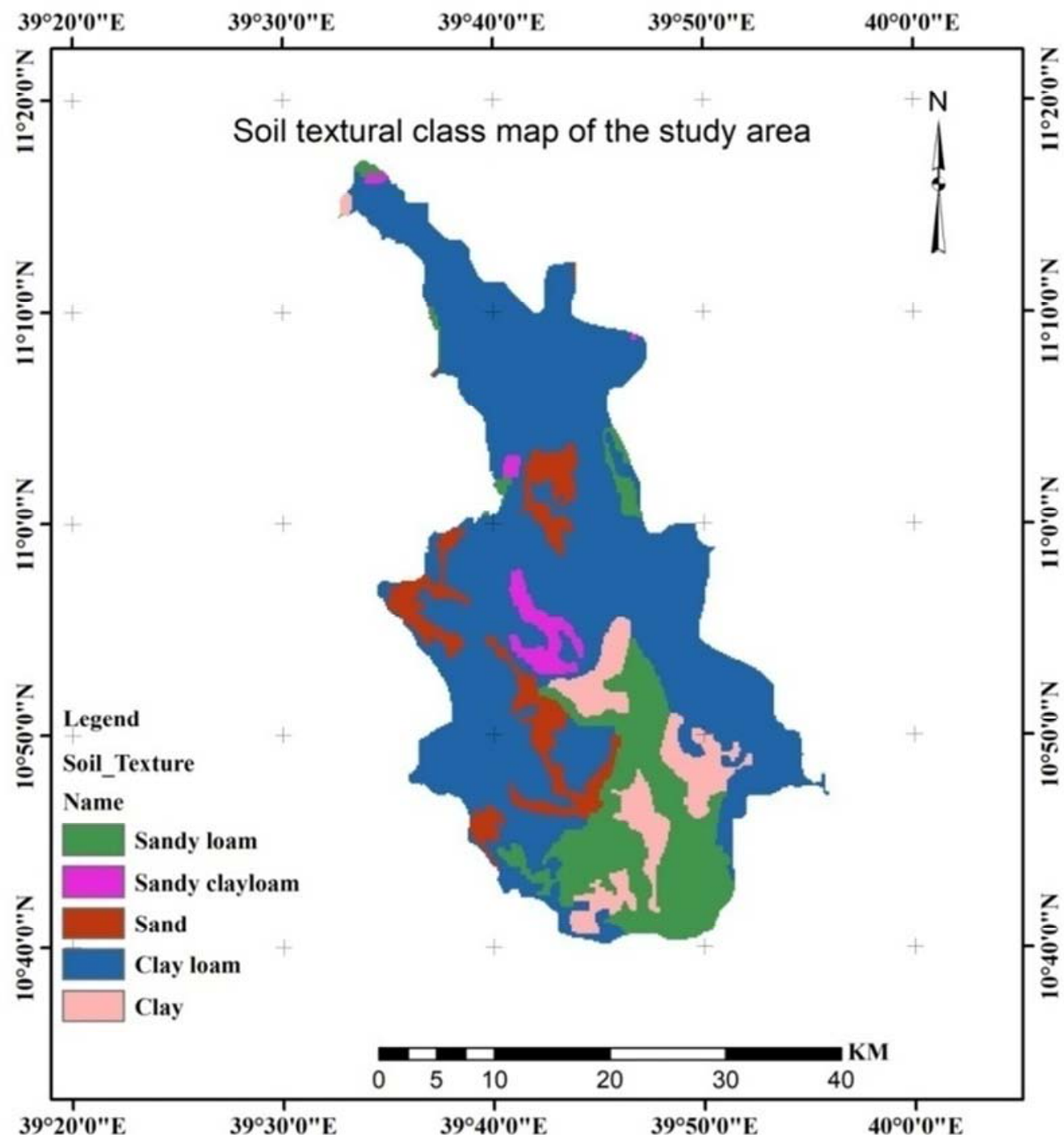

Figure 3. Textural class and distribution of soils in Borkena River catchment. 


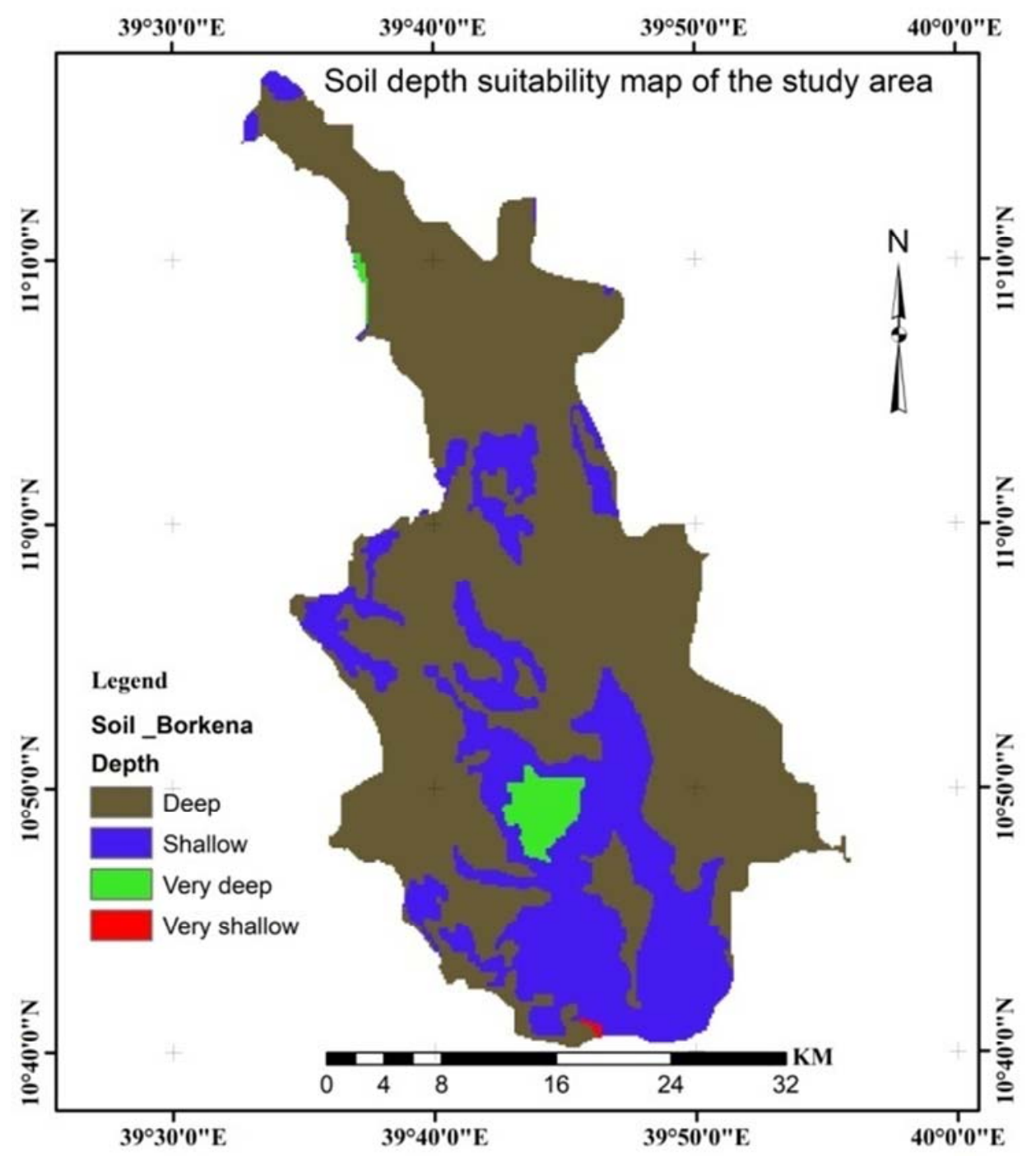

Figure 4. Soil depth class of Borkena River catchment.

Table 3. Areal distribution of textures class of Borkena River catchment soil.

\begin{tabular}{llll}
\hline Texture Class & Area (ha) & Area (\%) & Class \\
\hline Clay loam & 82,267 & 65.29 & $\mathrm{~S} 1$ \\
Clay & 9,739 & 7.73 & $\mathrm{~S} 1$ \\
Sandy clay loam & 3,183 & 2.53 & $\mathrm{~S} 2$ \\
Sand & 10,105 & 8.02 & $\mathrm{~S} 3$ \\
Sandy loam & 20,706 & 16.43 & $\mathrm{~S} 3$ \\
Total & 126,000 & 100.00 & \\
\hline
\end{tabular}

The soil depth of the study area was classified into four classes as shown Table 4 and Figure 4.

However, in relation to surface irrigation suitability based on FAO [13] it is classified into two groups highly suitable (S1) and temporally or permanently not suitable (N). A large portion of the River catchment was covered soils with deep to very deep depth $(72.03 \%)$ or highly suitable (S1) for surface irrigation practice and on the other hand around $27.97 \%$ of the soil depth was shallow to very shallow and classified as temporally or permanently not suitable $(\mathrm{N})$ for surface irrigation development.
Table 4. Soils depth class of Borkena River catchment.

\begin{tabular}{llll}
\hline Depth & Area (ha) & Area (\%) & Class \\
\hline Deep & 87,718 & 69.62 & $\mathrm{~S} 1$ \\
Shallow & 34,571 & 27.44 & $\mathrm{~N}$ \\
Very deep & 3,037 & 2.41 & $\mathrm{~S} 1$ \\
Very shallow & 674 & 0.53 & $\mathrm{~N}$ \\
Total & 126,000 & 100.00 & \\
\hline
\end{tabular}

\subsection{Slope and Euclidean Distance Suitability Analysis}

The slope suitability analysis of the River catchment for surface irrigation based on FAO [13] suitability classification was indicated in Table 5 and Figure 5.

The result shows that the following suitable classes, highly suitable (37.12\%), moderately suitable (30.41\%) and marginally suitable $(23.12 \%)$ area in the River catchment. Only $9.35 \%$ of the area has slope great than $8 \%$, which is temporarily or permanently not suitable. Since most of the area in the River catchment falls below 8\% slope which is a suitable range of slope classification for surface irrigation with minor modification to bargain the natural slope. 
Table 5. Slope suitability classification and area converge of each slope class.

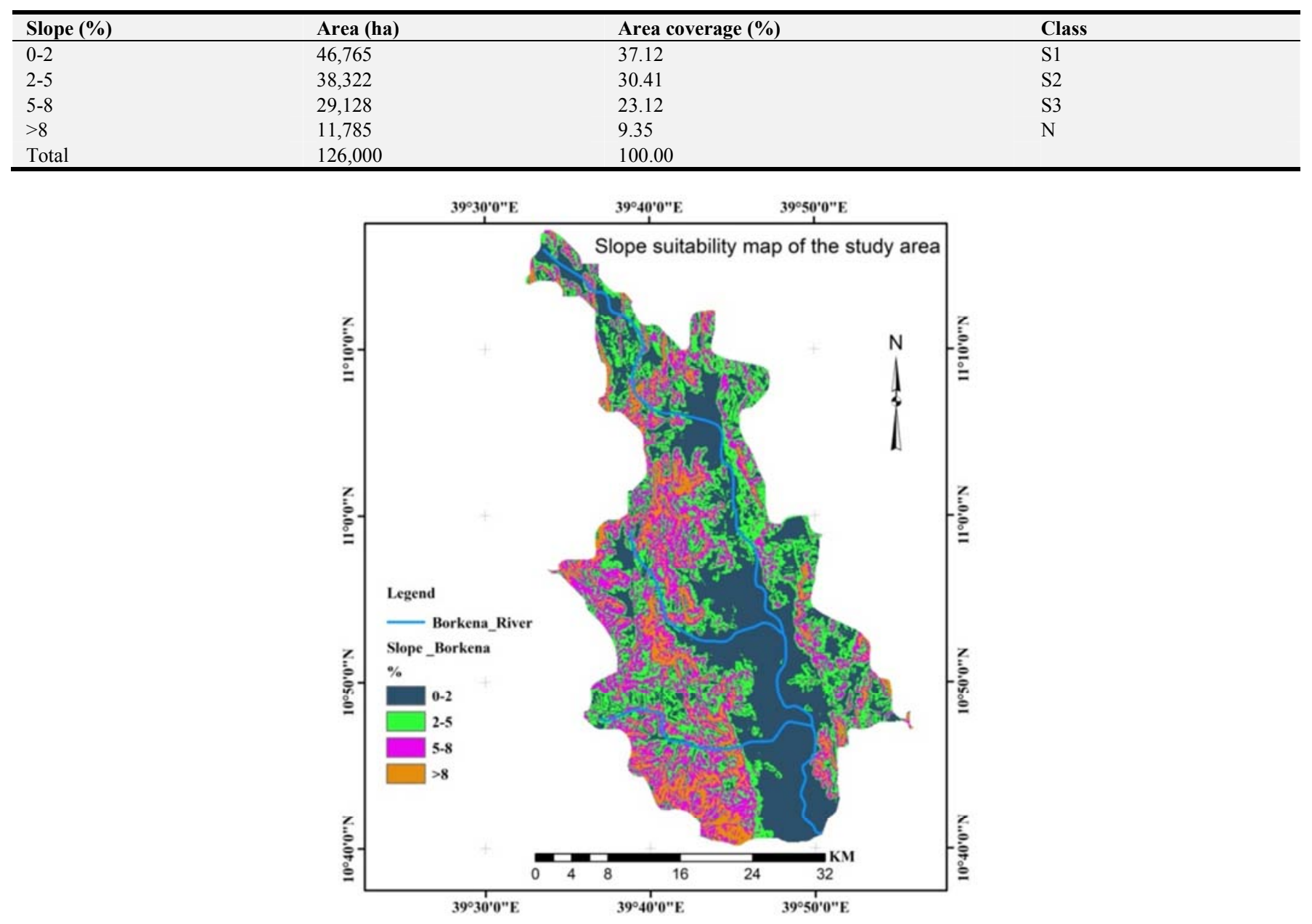

Figure 5. Slope classification of the study area based on FAO (1979) slope classification.

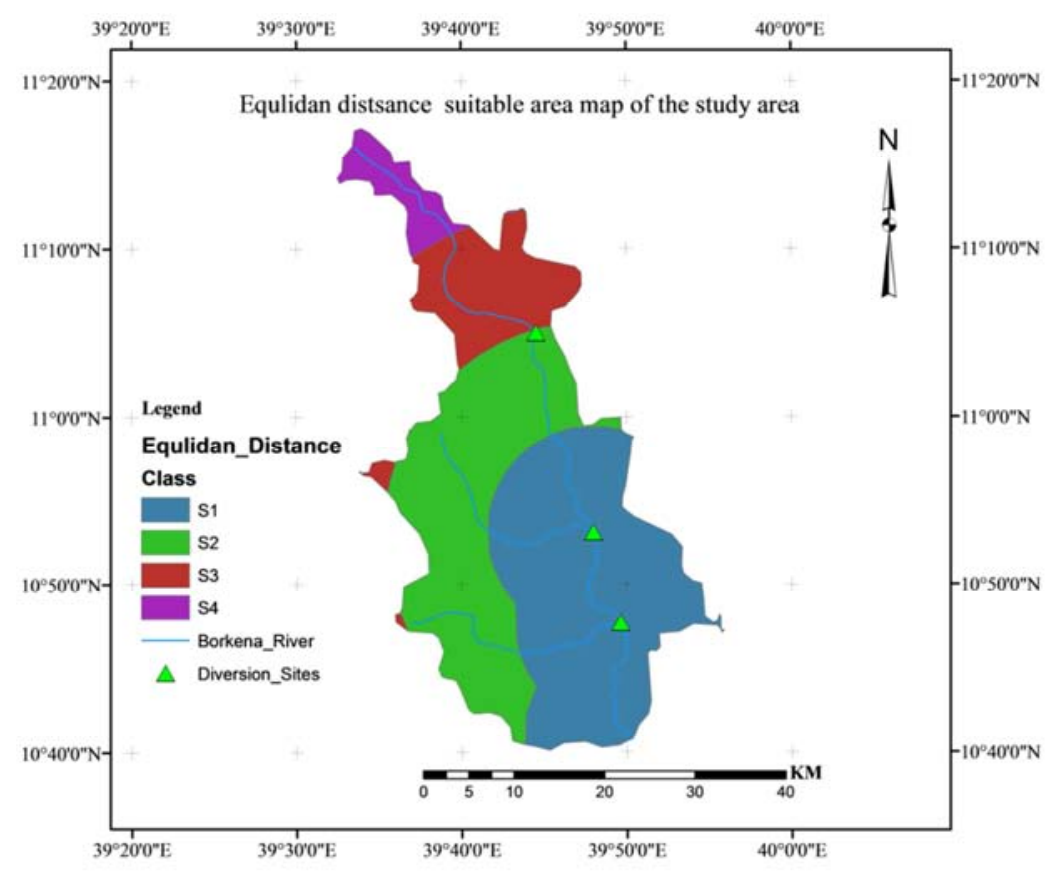

Figure 6. Suitable area of the River catchment based on distance from the water source. 
Euclidean distance is an important factor in the land suitability evaluation of surface irrigation because it spells out the amounts of lands which are close to the water source. For this study, as shown in Figure 6 and Table 6, nearly $43.86 \%$ of the area is the most suitable in terms of nearest to irrigation water supply point and considered as $\mathrm{S} 1$ in terms of suitability and also nearly $36.41 \%$ and $14.46 \%$ of the area are found moderately (S2) and marginally (S3) suitable for surface irrigation respectively. The remainder, 5.27\% area of the River catchment which found around the initial of the River catchment (Figure 6) is found under temporally or permanently not suitable for surface irrigation related to distance from water supply and conceded as $\mathrm{N}$ in terms of land suitability for surface irrigation.

\subsection{Land use/cover Evaluation}

Map in Figure 7 gives an overview of the existing land use/land cover in the River catchment of Borkena. Forest land, Shrub land, Acacia, Grassland, Agricultural land, bare land, and Settlement were common land use in the study area.

The areal extents and percentage of area converge for these land use/land covers in the study area are also given in Table 7. The majority of the area was under Agricultural land which accounts $57.03 \%$ (71,852 ha) from the total area being occupied by this land use/land covers. Forest land and shrub land dominates nearly $5.23 \%(6,592$ ha) and $27.60 \%$ $(34,785 \mathrm{ha})$ of the area respectively. The other land of the River catchment is covered by bare land (3.24\%), settlement (3.27\%), Grass land (2.12) and Acacia land (1.51\%). As shown in Figure 7, most agricultural land is found in the lower part of the River catchment around and near the outlets.

Table 6. Euclidean distance of irrigation area form potential diversion point.

\begin{tabular}{lll}
\hline Class & Area (ha) & Area (\%) \\
\hline S1 & 55,260 & 43.86 \\
S2 & 45,879 & 36.41 \\
S3 & 18,218 & 14.46 \\
N & 6,643 & 5.27 \\
Total & 126,000 & 100.00 \\
\hline
\end{tabular}

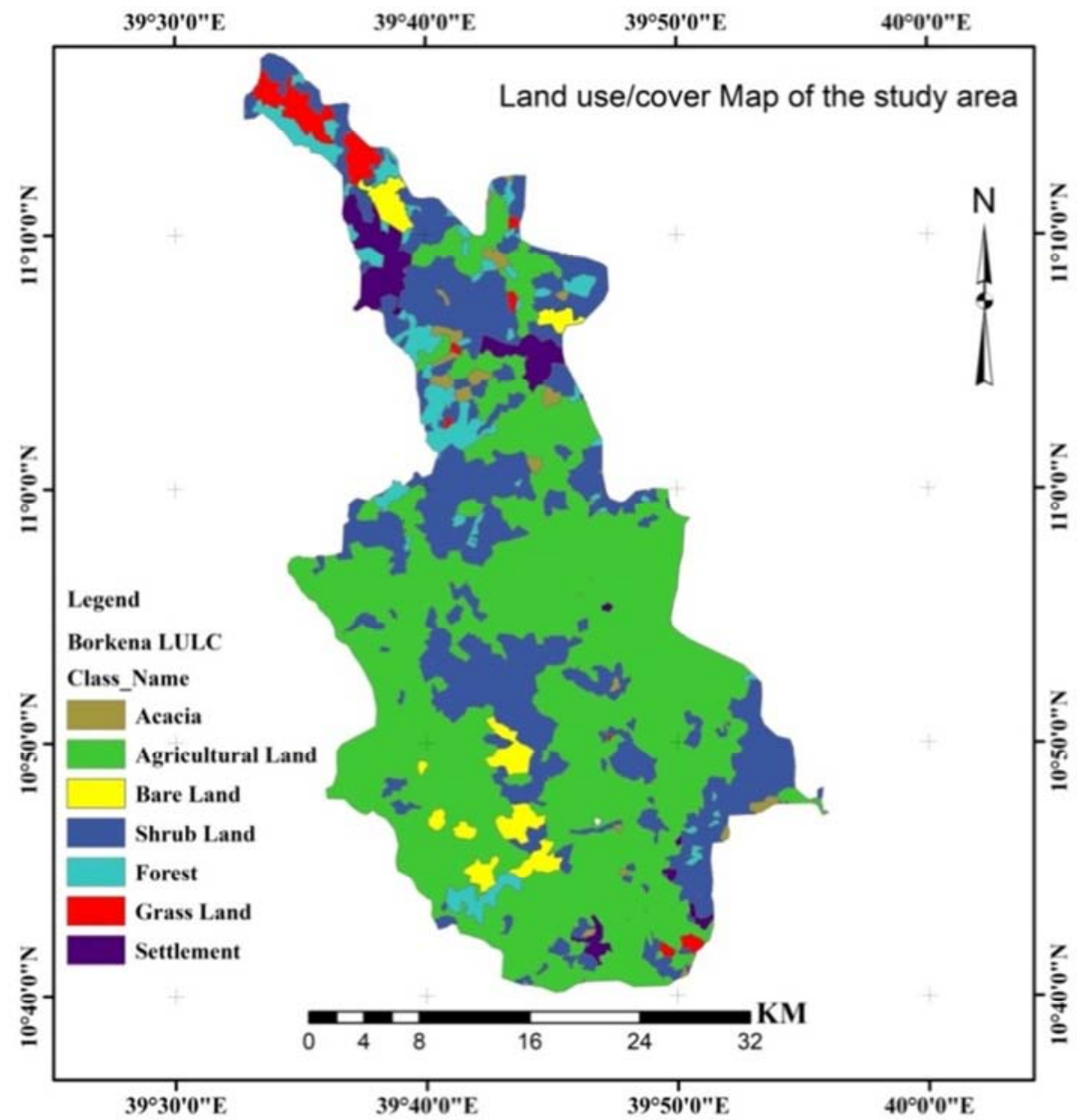

Figure 7. Land use land cover classification of Borkena River catchment.Table 7. Land use land cover of the study

\begin{tabular}{lllllllll}
\hline Land use & Acacia & Agricultural land & Bare land & Forest & Gras land & Settlement & Shrub land & Total \\
\hline Area (ha) & 1,898 & 71,852 & 4,082 & 6,592 & 2,677 & 4,114 & 34,785 & 126,000 \\
Area (\%) & 1.51 & 57.03 & 3.24 & 5.23 & 2.12 & 3.27 & 27.60 & 100 \\
\hline
\end{tabular}




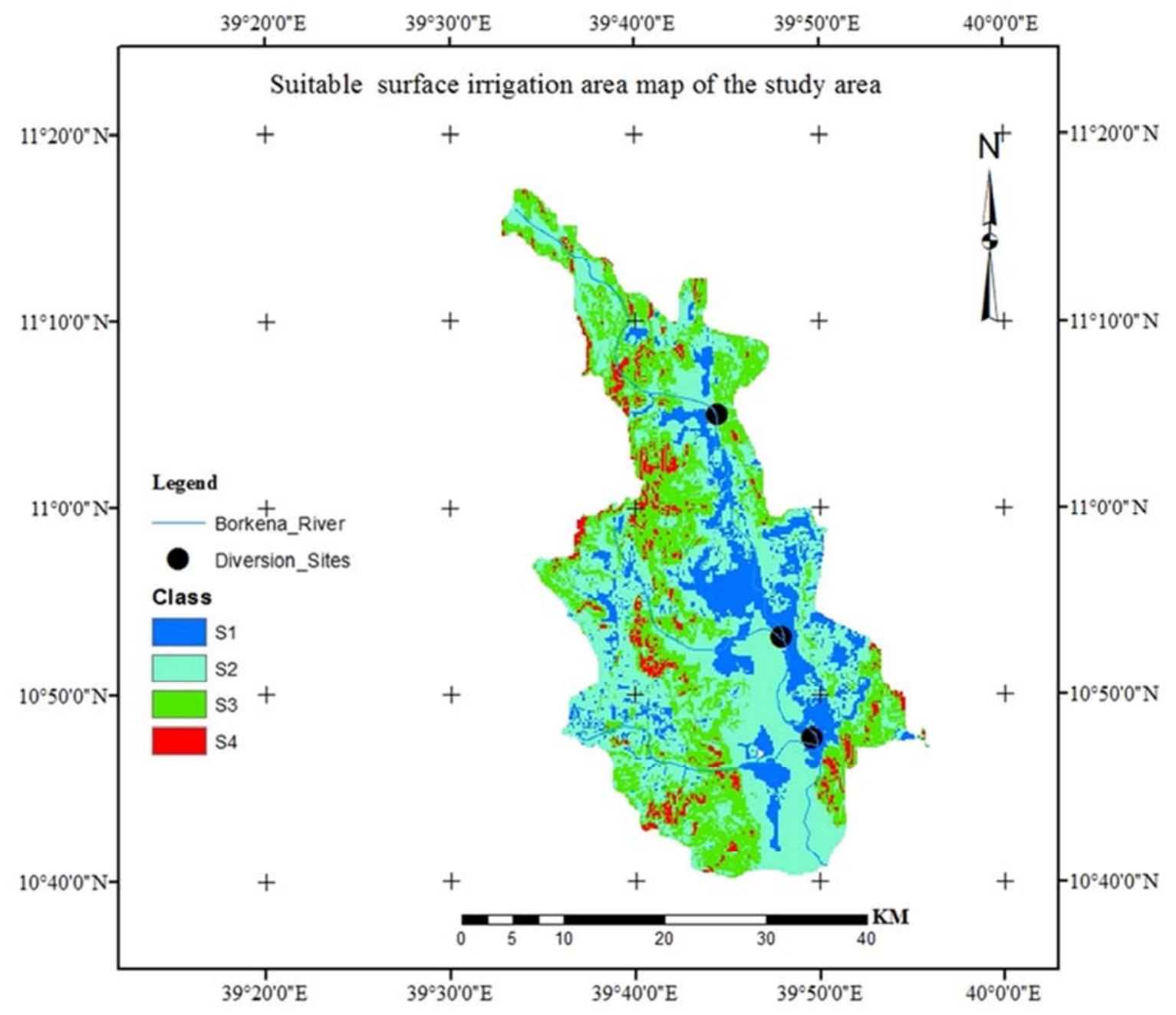

Figure 8. Distribution of suitable area for surface irrigation in River catchment.

\subsection{Weighing of Irrigation Suitability Factors}

Based on the interpretation of physical characteristics of the parameters (slope, soil texture, soil drainage, soil depth, land use land cover and Euclidean distance), the qualitative land evaluation for surface irrigation suitability implies that the majority part of Borkena River catchment was identified as from highly suitable to marginally suitable for surface irrigation.

Table 8. Surface irrigation suitable area of the River catchment.

\begin{tabular}{llllll}
\hline Class & S1 & S2 & S3 & N & Total \\
\hline Area (ha) & $11,589.73$ & $33,856.66$ & $22,690.86$ & $3,714.75$ & $71,852.00$ \\
Area (\%) & 16.13 & 47.12 & 31.58 & 5.17 & 100.00 \\
\hline
\end{tabular}

The last output of irrigation suitability model analysis which was involved by weighting of factors such as soil (soil texture, soil depth and soil drainage), slope, land use/ land cover, and distance from the water supply by restricted other land use for irrigation development without agricultural land and by considering the jointing point of tributary River in to the main River as potential reservoir or diversion sites (water supply point) indicated that most areas of the River catchment was moderately suitable for surface irrigation development as shown in Figure 8.

\section{Conclusions}

The results from the irrigation suitability analysis of the River catchment of Borkena based on the physical factor of surface irrigation suitability such as slope, soil texture, soil drainage, soil depth, land use/cover and distance from the water source indicates, $90.65 \%$ of slope, $72.03 \%$ of soil depth, $94.73 \%$ distance from a water source of the study area, $100 \%$ soil drainages and $100 \%$ of soil texture were identified in the range of highly suitable (S1) to marginal suitable (S3) for surface irrigation. But, when all the above physical suitable area determination factors were weighted together using weighted overlay in Arc GIS software by restricted other land use/cover for irrigation development without Agricultural land indicates only $16.13 \%$ highly suitable (S1), $47.12 \%$ moderately suitable (S2) 31.58 marginally suitable (S3) and 5.17\% non-suitable (N) area for surface irrigation development. So, according to this study with some modification and management for marginally suitable (S3) area of the River catchment, 68137.25 ha land of the River catchment was suitable for surface irrigation development. 


\section{References}

[1] World Bank. Ethiopia: Managing water resources to maximize sustainable growth. Country water resources assistance strategy. (36000), 119. 2006.

[2] Clarke, N., Bizimana, J. C., Dile, Y., Worqlul, A., Osorio, J., Herbst, B.,...Jeong, J. Evaluation of new farming technologies in Ethiopia using the Integrated Decision Support System (IDSS). Agricultural Water Management, 180 (August), 267 279. https://doi.org/10.1016/j.agwat.2016.07.023. 2017.

[3] Gashaw, T., Berhe, D. H. and Nigussie, A. 2014. Climate Change Adaptation and Mitigation Measures in Ethiopia', Article · May 2014, (March 2017).

[4] Awulachew S. B. 2010. Irrigation potential in Ethiopia Constraints and opportunities for enhancing Irrigation potential in Ethiopia Constraints and opportunities for enhancing the system International Water Management Institute Teklu Erkossa and Regassa E. Namara, IWMI Research Report, (May 2014).

[5] Dereje and Kidane, 2016. Assessment of the Impact of SmallScale Irrigation on Household Livelihood Improvement at Gubalafto (2016). doi: 10.3390/agriculture6030027.

[6] Meja, M., Bassa, M. and Mirkeno, T. 2020. Assessing the Challenges of Irrigation Development in Ethiopia: A Review', 9 (01), pp. 215-221.

[7] FDRE. Federal Democratic Republic of Ethiopia Ministry of Water Resource Water Sector Development Program Main Report. II (October). 2002.

[8] Mosissa, T. and Bezabih, B. 2017. Review on participatory small-scale irrigation schemes and small-scale rainwater harvesting technology development and its contribution to household food security in Ethiopia, 9 (March), pp. 54-63. doi: 10.5897/IJWREE2016.0700.
[9] Kassie, A. E. 2020. A Review Challenges and Opportunities of Irrigation Practices in Ethiopia, (January). doi: 10.9734/jerr/2019/v9i317016.

[10] LINPICO. Federal Government of Ethiopia Ministry of Finance and Economic development: public finance management assessment amhara regional government. 2010.

[11] Temesgen, K., and Yonas, A. Evaluating land suitability for irrigation purpose in Abaya district, Borena zone, Ethiopia. African Journal of Agricultural Research, 11 (46), 47544761. https://doi.org/10.5897/ajar2016.11438.2016.

[12] Bengal, W. Land suitability assessment for potential surface irrigation of river catchment Land suitability assessment for potential surface irrigation of river catchment for irrigation development in Kansai watershed, Purulia, West Bengal, India. Sustainable Water Resources Management, (July 2017). https://doi.org/10.1007/s40899-017-0155-y 2018.

[13] FAO (Food and Agriculture Organization). Irrigation potential in Africa: A basin approach FAO Land and Water Bulletin 4. 1997.

[14] FAO (Food and Agriculture Organization). 2001. International Programme for Technology andResearch in Irrigation and Drainage Asia Drainage Programme for the Humid TropicsProject Proposal IPTRID SecretariatFood and Agriculture Organization of the United Nations, Rome, Italy, Organization.

[15] FAO (Food and Agriculture Organization).2013.Water quality for agriculture Food and Agriculture Organization, Irrigation and Drainage Papers. http://www.fao.org/docrep/003/t0234e/t0234e00.htm (accessed on March 11, 2018)

[16] FAO (Food and Agriculture Organization). The Future of Our Land: Facing the challenge- Guidelines for Integrated Planning for Sustainable Management of Land Resources, pp. 1-88. doi: 9251043669. 1999. 